\title{
ESPACCO INVENTADO: O TEATRO PÓS-DRAMÁTICO NA ESCOLA
}

\section{Carminda Mendes André*}

UNESP

RESUMO: Com a publicação da lei n. 9394/96, a arte integra-se ao currículo do ensino básico como área de conhecimento. Neste ensaio, problematiza-se essa nova condição da arte na escola, refletindo a particularidade da experiência artística em relação às outras disciplinas, de modo a não se descaracterizar o que é próprio dela. A partir do entendimento de que a presença da arte é provocadora de mudanças, busca-se observar aquilo que, na escola, é necessário "ser tocado" por ela. Esse olhar investigativo flagra uma cena de destruição, com problemáticas muito próximas daquelas expressas pelo teatro contemporâneo. Com isso, sugerese aproximar a realidade escolar de formas do teatro pós-dramático, com o intuito de inventar espaços que possam vir a ser coletivos e que acolham o que se chamou de "trocas de intimidades". Dessa aproximação, reitera-se o conceito de conhecimento como invenção, defendido por Michel Foucault, e detecta-se a necessidade de elaborar uma atitude docente que seja provocativa e crie ações educativas de tipo estratégico.

PALAVRAS-CHAVE: Teatro Pós-Dramático; Educação; Conhecimento

\section{INVENTED SPACE: POSTDRAMATIC THEATER AT SCHOOL}

ABSTRACT: With the publication of the law $n^{\circ}$ 9394/96 in Brazil, the art belongs to the curriculum of the basic education as knowledge field. In the essay "The invented space: the post-modern condition in the public brasilian school" we suggest to render problematic this new condition about art in the school, reflecting over the particularity of the artistic experience in respect to the other

\footnotetext{
* Doutora pela Faculdade de Educação da Universidade de São Paulo - USP. Integra-se ao quadro docente do Departamento de Artes Cênicas, Educação e Fundamentos da Comunicação do Instituto de Artes da Universidade Estadual Paulista "Júlio de Mesquita Filho” - UNESP - São Paulo, Brasil. E-mail: carminda.stenio@uol.com.br
} 
disciplines in a way to not deprive of the characteristics of what is proper to art. Starting from the understanding that the art presence is provoker of changings, we seek to observe what, in the school, is necessary to be touched by it. This investigative look meets a destruction scene, with a set of problems very close to that ones expressed by the contemporary theater. With this, we suggest to approach the scholar reality to the post-dramatic theater forms with the intention of invent spaces that might be collectives and welcome what we called "intimacy changes". From this approach, we reiterate the concept of knowledge as invention defended by Michel Foucaut and we find out the necessity of elaborate an academician attitude that be provocative and which creates strategic kind of educational actions.

KEYWORDS: Education; Post-Dramatic Theater; Knowledge

Em 1996, com a publicação da lei n. 9394/96, a arte ganha novo posicionamento no espaço das instituições de ensino básico brasileiras, quando deixa de constituir-se como atividade escolar, passando a ser definida como área do conhecimento. Diante desse fato, muitas pesquisas voltam-se para a análise dos programas de ensino, no intuito de entender de que maneira a arte pode integrar-se aos projetos pedagógicos e dialogar com as disciplinas já existentes. No entanto, nem sempre se pergunta qual a necessidade da arte na escola e o que significa nomeá-la área do conhecimento no currículo da educação básica. Alerta-se para o cuidado de não tornar a atividade artística uma disciplina escolar, sistematizada nos mesmos moldes que os programas de ensino já existentes, e embasados em modelos da ciência, pois, dessa maneira, a tendência é desvirtuar os conhecimentos específicos da arte.

Ao se diferenciar ciência e arte, distingue-se o conhecimento resultante da experiência artística e o da experiência científica. Enquanto a ciência compreende o conhecimento como o resultado de um projeto de pesquisa, com hipóteses e experimentos para sua confirmação, a experiência artística acontece a partir de um início preciso, que produz movimento e não se poderá prever o sentido tomado. Nela, sujeito e objeto se fundem e se confundem. A ação criativa é processo e produz possibilidades, enquanto o experimento científico é projeto e deve produzir produtos acabados. Sendo assim, um programa de ensino em arte, que objetive a experiência criativa, não conduz alunos para a realização de uma finalidade técnica ou conteudística e não objetiva a realização de um produto acabado. 
Sobre isso, o artista plástico Hélio Oiticica escreveu, certa vez, que a função do artista não é a de criador das coisas, posto que elas já estão aí, mas que a função da arte é a de mudar o valor das coisas'. Em concordância com Oiticica, ao retornar à escola e observar a presença do desejo pela arte, uma hipótese se afigura: a presença da arte, caso seja uma necessidade, provocará mudanças de valores nas coisas que toca. Sendo assim, se a arte é realmente necessária para a educação básica, sua ação provocará crises.

Quando se diz aqui "necessidade da arte", faz-se referência à necessidade de mudanças de algo que nos é vital'. Se a arte é necessária, é porque sem ela morremos em algo. Se a educação é necessária, é porque sem ela também morremos em algo. O que, então, é vital que a arte mude na escola para que ela não morra? E, por outro lado, o que é vital na arte para que sua presença se justifique no espaço escolar?

\section{O QUE É VITAL NA ARTE?}

Para Teixeira Coelho, a arte é vital para os indivíduos quando "procura e viabiliza o êxtase, o sair para fora de si, sair do contexto em que se está para ver outra coisa, para ver melhor, para ver além, para enxergar sobre, acima, por cima, para ver por dentro" (COELHO 2001, p. 28-29). Nesse sentido, o "êxtase" é a experiência que possibilita a transformação do sujeito e do mundo a partir de um efeito de distanciamento. Tal experiência é fundamental porque ajuda a reescrever conceitos, representações da realidade e identidades.

Entretanto, o êxtase também está associado às experiências religiosas, com os dramas-rituais e seus espaços sagrados. Nesse parentesco, o teatro confirma sua vitalidade como ato inaugural de espacialidades coletivas; confirma seu potencial simbólico de fundar espaços que se podem chamar de públicos, no sentido de serem espaços de possíveis trocas de experiências entre sujeitos diferentes, tornando-os próximos. Sem confundir "público" com popularidade e com quantidade de espectadores, o espaço tornado público pela ação da arte sugere a aproximação dos artistas com a platéia. Nesse sentido, credita-se ao espaço inventado, fundado pelo evento artístico, a função de aproximar o que está disperso. Desse modo, a arte funciona como "ação cultural" .

$\mathrm{Na}$ perspectiva do olhar para as formas do teatro contemporâneo, Hans-Thyes Lehmann, parafrasenado Heiner Muller, afirma que a "tarefa da arte é tornar a realidade impossível". Afirma ainda que, para alcançar tal objetivo, os artistas, desde as vanguardas históricas, utilizam o 
procedimento da "interrupção" para provocar o estranhamento daquilo que se afigura familiar para o público, isto é, "interrupção" também como choque. Por seu efeito, pode-se dizer que a "interrupção" proporciona o êxtase, no mesmo sentido dado por Teixeira Coelho, pois nos distancia e nos faz ver "além, de cima, por cima, por dentro". Ou seja, a "interrupção", ao funcionar como choque e como distanciamento, torna a realidade não mais reconhecível, não mais possível, fazendo-nos pensar a respeito.

Entretanto, os modos modernos de produzir "interrupção" já estão desgastados e não mais surtem o efeito desejado. Assim, pode-se afirmar que um dos problemas da arte, hoje, é elaborar formas artísticas que provoquem a "interrupção". Para Lehmann, o teatro pós-dramático é uma maneira de enfrentar essa problemática, comum a toda a arte da contemporaneidade: "E essa questão comum é: como podemos, numa sociedade como a em que vivemos hoje, de mídia e de massa, criar através do teatro essa situação de interrupção?” (LEHMANN, 2003, p. 11)

Retomando as questões que deram início a este debate, pode-se afirmar que, por meio do teatro, é possível inventar espaços que podem vir a ser coletivos e possibilitam a experiência do êxtase, do distanciamento e das formas de "interrupção". Para tanto, essa espacialização não pode constituir-se de uma finalidade que direcione os acontecimentos que aí se tornem presentes.

Daí, pode-se dizer que, sem a presença da arte em seu cotidiano, os sujeitos perdem um privilegiado espaço, na vida cultural, para exercitar a transformação e o estranhamento de si e do mundo. Nesse sentido, o sujeito privado da experiência com a arte é um sujeito que se aterroriza com as mudanças e com as diferenças; ou, por outro lado, um mundo privado da experiência artística é como uma fotografia em papel que, estática, se desintegra na ação do tempo. Disso, pode-se afirmar que esse mundo, que sofre a falta de arte, constitui-se pelo terror da ação do tempo.

\section{O QUE É VITAL QUE A ARTE TOQUE NA ESCOLA PARA QUE ELA NÃO MORRA?}

O que dizer da necessidade da arte dentro da escola? Onde se pode perceber a privação da experiência com a arte no ambiente escolar? Não é preciso fazer análises profundas das políticas educacionais ou dos projetos pedagógicos, ou ainda dos programas de ensino, para perceber que a arte marca sua ausência na maioria das escolas públicas paulistas. 
Essa ausência está sinalizada pelo terror à ação do tempo, ao envelhecimento, terror à morte. Para observar sinais da falta da experiência da arte nas escolas, convida-se o interlocutor a andar pela cidade de São Paulo com o único propósito de observar os elementos que envolvem o cotidiano das escolas públicas.

O que dizer da arquitetura de uma escola pública quando comparada à planta baixa de uma penitenciária de porte semelhante? Nessa comparação, pode-se constatar um modelo institucional que não diferencia o uso de seus usuários, de modo que tudo pareça igual. Outros objetos se dão para o olhar perscrutador que se aproxima de uma escola: o que dizer das calçadas esburacadas, da conservação de muros e paredes, tomados de pixações de total mau gosto? O que dizer das grades externas e das que separam ambientes internos? E os portões trancados: como é trabalhar em um lugar trancado? $\mathrm{O}$ que dizer do sistema interno de câmeras de segurança e das rondas policiais escolares? Em um país tropical, como haver aulas com um teto de zinco sobre as cabeças? O que dizer da visão de destruição com os bebedouros de torneiras arrancadas, dos banheiros, das cadeiras e carteiras? E os alunos com armas de fogo e a violência de palavrões arremessados por alunos e professores? O que dizer do mau humor generalizado de funcionários, serventes de limpeza e merendeiras, cuja voz se ouve em gritos a esmo? O que dizer dos dispositivos governamentais para punir as escolas pelo número de funcionários com licença médica e pelo mau desempenho dos alunos em exames elaborados fora da escola?

Por parte da opinião pública, há certa dificuldade em admitir o modelo panóptico ${ }^{4}$ nas intuições de ensino - básico ou superior - na cidade de São Paulo. A presença de câmeras de vigilância, catracas, grades e rondas policiais escolares está mais próxima da idéia de segurança do que de vigilância, e isso confunde. No entanto, há ambigüidade nessa situação: por que tais práticas existem nos espaços e no entorno da maioria das escolas paulistas de ensino básico, tanto públicas quanto particulares, e nestas a sofisticação dos instrumentos é maior? Que tipo de educação se faz com esses instrumentos? Somando-se a esse quadro de destruição, observa-se que a arte está sendo apropriada ou para instrumentalizar a fixação do conteúdo de outras matérias ou para a realização de espetáculos em datas comemorativas e em final de ano, para a satisfação de pais e diretores, posto que os professores são obrigados a mostrar "resultados visíveis" em apresentações públicas. A afirmação de funções decorativas para a arte demonstra, mais uma vez, a ausência desse naquele ambiente. 
Entende-se que o desafio do pesquisador é compreender a violência no ambiente escolar paulistano, sem cair nas opiniões do senso comum, que "encontra culpados" na prática da corrupção e no desvio de verbas ou na falta de educação dos alunos e na ausência dos pais. Sem negar esses fatores como possíveis causadores dessa violência, deseja-se olhar outros cantos da escola e buscar relações entre essa cena de destruição e o aumento dos casos de tragédia causados por jovens com armas de fogo, dentro ou fora das escolas, no mundo das Américas. Algo acontece que não é explicitado. O que seria? Desconfia-se que há um conflito nãoadmitido por aí. Uma guerra velada é dizer demais?

Tal fato não é privilégio da escola, pois se pode afirmar que essas questões são, hoje, um desafio de todo indivíduo que deseja se manter sujeito de si e do mundo. Michel De Certeau (1994), retomando as perspectivas de Foucault sobre o projeto civilizatório da modernidade no ocidente judaico-cristão, organizado a partir do modelo panóptico e de suas teorias sobre a microfísica do poder - de que este é algo que não está fora, mas impregnado no minúsculo das práticas cotidianas -, sai às ruas à procura de ações populares que denotem o enfrentamento dessa hiperdisciplina que deforma. Nesse caminhar de andarilho, o autor parte da seguinte questão:

Se for verdade que por toda a parte se estende e se precisa a rede da "vigilância”, mais urgente ainda é descobrir como é que uma sociedade inteira não se reduz a ela: que procedimentos populares (também "minúsculos" e cotidianos) jogam com os mecanismos da disciplina e não se conformam com ela a não ser para alterá-los; enfim, que "maneiras de fazer" formam a contrapartida, do lado dos consumidores (ou "dominados"?), dos processos mudos que organizam a ordenação sociopolítica. (DE CERTEAU, 1994, p. 41).

Essas "maneiras de fazer", De Certeau as conceitua como "táticas antidisciplinares", posto que são maneiras que os consumidores - os "dominados" - inventam para se apropriar daquilo que lhes falta. Como exemplo, podem ser citadas as apropriações do espaço público feitas por pessoas despossuídas de casa - os mendigos - e que encontram espaços não-vigiados para criar sua intimidade. Essas "maneiras de fazer" são ações que agem contra as redes de vigilância e, por isso, diz o autor, funcionam como atos conscientes desses dispositivos de vigilância. Desse modo, De Certeau afirma haver uma cultura que aparece entre a população, silenciosa, constituída de ações que são desvios das redes de vigilância sobre o cotidiano hipervigiado.

$\mathrm{Na}$ observação de como trabalham alguns coletivos de artistas ${ }^{5}$, percebe-se a existência de uma cultura que brota do asfalto, das ruas do 
centro da cidade de São Paulo, distinta daquela chamada de culta e de popular, mas que muito se aproxima das observações de De Certeau na sua Paris. A arte que ali se expressa não é de profissionais especialistas em arte; ali se encontram estilistas, músicos, atores, escritores, artistas plásticos constituídos com elementos da rua. É uma arte da rua. Mas dificilmente ela se mostra como arte pura, pois está, em sua maioria, atrelada a alguma necessidade primária: religiosa - como é o caso dos pastores que desenvolvem modos de declamação interessantíssimos para expressar sua fé e atrair fiéis - ou de sobrevivência - como é o caso dos inventores de "oráculos" para ler a sorte dos indivíduos ou as táticas cênicas de vendedores ambulantes, além de tantos outros exemplos.

Essas são manifestações culturais resultantes de necessidades de quem precisa burlar as regras institucionalizadas do lugar público e garantir a própria sobrevivência, reinventando novos usos não-autorizados para esse lugar. Longe de menosprezá-las, o que aqui se pretende é dar legitimidade a elas, pois é graças a sua aparição que De Certeau constata a atitude inventiva de uma sociedade que não se deixa aprisionar pelas tais redes de vigilância.

Outros exemplos dessa "cultura popular" podem ser observados. Veja-se a ação dos pixadores que se dedicam a burlar os mecanismos de segurança, correndo risco de morrer, executando verdadeiros malabarismos em arranha-céus de grandes cidades brasileiras para deixar mensagens em um código para iniciados. Ou então atitudes como a do grupo musical paulistano Barbatuques ${ }^{6}$, que desenvolve música com sons retirados do corpo, eliminando completamente o uso de instrumentos musicais convencionais. Ou ainda artistas plásticos que saem nas ruas desenhando e pintando bueiros; mais, o próprio grupo Alerta!, que intervém com cenas-jogos em praças e ruas juntamente com camelôs. Todos eles têm em comum a atitude de usar materiais desprezados e realizar soluções artísticas que confrontam a especialização, a informatização dos meios de produção, a cultura industrial do entretenimento e contra-argumentam com os mecanismos impostos de modernização.

Para atuar nesse campo, tem-se desenvolvido uma atitude de andarilho para descobrir espaços do "nós despossuído", dos sem destino, daquilo que ainda não tem identidade. A atitude distanciada - porém não neutra - torna-se condicional. E para se alcançar um processo de invenção de alteridades, é preciso um esforço de atenção por parte dos participantes, para que possam capturar as provocações que a cidade - ou a escola - oferece, mas, ao mesmo tempo, não se prendendo a desejos 
individualistas. Ao receber provocações externas, o atuante sofre a experiência no sentido dado por Jorge Larrosa (2004), que a conceitua como um momento de exposição do sujeito, posto que ele estará aberto a sofrer ocorrências encontradas pelo caminho.

Do ponto de vista dessa cultura que fura a rede de vigilância, interpreta-se a violência na escola como efeito de uma "maneira de fazer" que explicita o mal-estar de um corpo assujeitado e hiperexposto pelas redes de vigilância, sintoma de que há cada vez menos espaços livres para o exercício da interioridade. Esse corpo, jovem ou não, torturado pela vigilância sobre a qual ele não sabe bem o porquê, muitas vezes, grita.

$\mathrm{Na}$ perspectiva observada de outro lugar, a cena que se afigura na escola sinaliza o rompimento do contrato social vigente e o conseqüente desaparecimento dos vínculos comunitários entre os usuários do lugar. Assim, aquilo que mostra a metáfora da guerra é a necessidade de se repensar o espaço da escola, de reescrever os princípios da educação e refletir novamente sobre os princípios do contrato social, de modo que todos possam participar. Ao se querer que a educação escolar torne-se algo vivo e positivo para todos, luta-se para que todos os indivíduos aí presentes percebam a necessidade de se desarmar a rede da vigilância, conquistar espaços livres, para que eles mesmos não desapareçam como sujeitos de si e do mundo.

\section{COMO O TEATRO PÓS-DRAMÁTICO PODE PROVOCAR A INVENÇÃO DE ESPAÇOS LIVRES?}

Com o quadro que se mostra à frente, indaga-se se não seria interessante apropriar-se da arte na escola para criar espaços livres com a única finalidade de proporcionar "encontros de intimidades", distanciamento, êxtase. Ou ainda, espaços que promovam o diálogo entre os diferentes personagens sociais - diretor, coordenador, professores, alunos, funcionários e pais -, para que todos possam entender os discursos que tais papéis sociais representam.

Diante disso, volta-se ao próprio da arte e pergunta-se: como criar formas que provoquem a "interrupção" nos espaços e nos cronogramas escolares? Como "estar aí", com a arte, deixando às claras as contradições ao invés de mascará-las? Como tornar impossível essa realidade metaforizada pela cena da guerra?

Ao se mergulhar nesse enxame de questões, se poderá encontrar, nas formas pós-dramáticas, valiosas ações que, se tornadas educativas, podem ajudar os educadores a posicionar o teatro dentro da educação 
básica. Entende-se por ações educativas aquelas que intervêm nas práticas relacionadas aos modos e meios de produzir conhecimento e, portanto, ações que se relacionam aos modos de se criar e dominar as coisas, como também, os estudos de seus usos. O que se quer reescrever são as relações entre os indivíduos e, nos espaços inventados, criar temporalidades para o exercício da subjetividade. Sendo assim, de que maneira as formas pósdramáticas podem contribuir para a conquista dessa construção?

Se se entender o teatro pós-dramático resultante de reflexões sobre a questão colocada por Lehmann - "como provocar a interrupção em um mundo de mídia e de massa?" -, é possível detectar, em suas formas, procedimentos que levam o público a estranhar os discursos e os modos como a mídia conduz o indivíduo a comportar-se como massa. Um desses procedimentos dá-se pela estrutura das formas abertas que trazem em si a proposta da interatividade. Essa participação - potencial ou real - oferece ao público uma experiência de sujeito ao atribuir-lhe responsabilidade sobre o acontecimento artístico. Essa participação, diferente daquela do teatro épico de Brecht - o distanciamento reflexivo - , é corporal. Em vez de estar apenas representada na cena, ela é presencial. Em alguns eventos, a participação proveniente da ação do público é indireta, entretanto há eventos em que a ação do público funda a cena. A participação não é um entretenimento, mas uma proposta de atitude, um comportamento político.

Por essa razão, compreende-se que tal participação - potencial ou real-, presente nessas formas, pode mediar os conceitos de arte e ensino, funcionando como ação educativa e como exercício para uma ética comunitária. Por meio dela, provoca-se a "interrupção" e, por exemplo, o questionamento da educação exercida por meio de instrumentos de vigilância, dos conteúdos das disciplinas, dos modos como as relações são estabelecidas na hierarquia existente entre cargos e funções dentro da escola - categorias de indivíduos: diretores e coordenadores, professores e alunos, ex-alunos, funcionários em geral, pais.

A interação flagra modos de apropriação individualistas como também dá oportunidade para que o participante experimente outras maneiras de se apropriar do evento artístico. Como coloca Lehmann, essas formas "têm a ver com a relação que cada espectador estabelece com as coisas que estão acontecendo" (LEHMANN, 2003, p. 13). Tal fato nos esclarece que aquilo que se produz nos eventos artísticos pósdramáticos, seu "acontecimento", é constituído por escolhas individuais, pela ética adotada pelos indivíduos participantes. Refletir sobre o aconte- 
cimento é, de certa forma, pensar sobre os comportamentos presentes naquele público.

O aspecto educacional que se mostra a partir dessas formas abertas indica que a realidade é algo a ser construído permanentemente, é algo móvel, incomensurável e, do mesmo modo, assim a arte. A idéia absoluta de verdade desaparece e, em seu lugar, brotam verdades que podem mudar permanentemente de figura, tudo dependendo do posicionamento e das necessidades do sujeitos que a produzem.

\section{O QUE A ARTE PODE TOCAR NO PROCESSO EDUCATIVO?}

Ao repensar Nietzsche, Foucault (2005) defende o conhecimento como uma atividade de invenção bumana e desmistifica a idéia de um instinto para o conhecimento. Em tal perspectiva, o indivíduo não vai em busca do conhecimento como impulso de uma natureza inclinada para o esclarecimento, para a curiosidade do saber, sem que algum interesse de ordem política o leve a isso. O conhecimento torna-se uma das estratégias que os homens adotam diante de algo que quer e que precisa dominar; o desejo por conhecimento é motivado pela busca de algo de que temos necessidade e que nos falta.

Ao aproximar tais interpretações da realidade da escola, a educação amplia sua função de divulgadora dos resultados dos projetos científicos ou, no caso do teatro, para além da alfabetização do indivíduo na linguagem da cena produzida por profissionais. Desse modo, a educação adquire a qualidade de se tornar um lugar de invenções, um lugar para se pensar estrategicamente, levando os sujeitos do processo de ensino/aprendizagem a conhecer modos de apropriação das coisas e, quiçá, provocando-os a inventar táticas ou, dizendo de outro modo, "maneiras de fazer" para alcançar aquilo que lhes é vital e que lhes falta.

Nessa perspectiva educativa, não há sentido em ensinar o "como se faz", "técnicas do fazer" teatro; ao contrário, suas formas afloram no bojo das necessidades e da falta de algo que surge entre os sujeitos no processo de ensino/aprendizagem. Sabe-se que tais necessidades não aparecem ao acaso, mas que precisam ser provocadas para sair do silêncio. Isso quer dizer que o modo e a maneira de atuar do professor são de fundamental importância. A ação de sua docência é aquilo que provoca, pois é ela que funcionará, em primeira instância, como "interrupção".

A compreensão de que o conhecimento colhido - as formas artísticas estudadas e produzidas pelo grupo - é resposta às suas provocações é dado fundamental para a orientação do professor. Se ele apresen- 
tar aos alunos as problemáticas de um mundo colonial, os conhecimentos gerados provavelmente girarão em torno desse tema. Porém, se ele apresentar contradições que envolvam os sujeitos na atualidade, o conhecimento produzido aproximar-se-á do mundo em que essas formas são geradas. Assim, o educador que conheça as problemáticas que envolvem as produções culturais do ensino e da arte da atualidade terá melhores condições de inventar estratégias que funcionem como "interrupções", produzindo estranhamentos nas imagens de realidade que daí emergem.

Para ilustrar a noção de ação educativa de tipo estratégico, apresenta-se a seguir uma historieta da cultura zen, de autoria anônima, intitulada "A arte da luta":

Havia uma família que tinha um pequeno sítio. O pai trabalhava de sol a sol para garantir que a propriedade ficasse para seus dois filhos quando morresse. Um dia, o pai ficou doente e, antes de morrer, repartiu a propriedade em duas metades iguais, pedindo que os irmãos prestassem ajuda mútua para torná-la cada vez mais produtiva.

E assim aconteceu até que o filho mais velho, casado, insuflado pela mulher, achou que, por ser casado, teria mais necessidades que o irmão mais novo, solteiro. E assim exigiu do irmão, à força, que lhe fosse entregue mais terra. Acuado, o irmão solteiro deixou seu irmão casado ocupar mais espaço de sua terra. Mas a mulher do outro, não satisfeita, convence o marido a conseguir toda a propriedade. O mais novo, não aceitando, acaba por ser expulso de suas terras, posto que o mais velho era muito mais forte.

Sem dinheiro, machucado, o jovem solteiro tornou-se um pedinte errante. Um dia, enquanto caminhava em um vilarejo, observou a presença de vários monges Shaolin comprando comida. Sabia que aqueles monges eram bons em artes marciais. Se pudesse aprender - pensou -, poderia expulsar seu irmão das terras. Seguiu-os, então, de perto e assim que chegaram ao templo pediu para ver o chefe. Contou para o chefe que sofrera uma grande injustiça, que seu irmão apoderara-se de suas terras e que gostaria de aprender a lutar para poder recuperá-las.

$\mathrm{O}$ chefe, que era um mestre na compreensão das necessidades humanas, ponderou por alguns instantes e disse:

- Se você estiver realmente decidido a enfrentar um treinamento duro e difícil, você será aceito como aluno aqui.

Aceitando o desafio, no dia seguinte, no amplo terreno do mosteiro, o jovem errante encontrou-se com o mestre, que carregava um bezerrinho no colo, em frente a um pequeno salgueiro, e disse ao aprendiz que, antes de aprender a arte da luta, ele deveria ficar forte. Para isso, o fez segurar nos braços o bezerrinho, instruindo-o a pular sobre o salgueiro 50 vezes de manhã e 50 vezes à tarde.

$\mathrm{O}$ aprendiz, obediente, executou a tarefa durante dias, meses e anos. O bezerro havia virado uma vaca e o pequeno salgueiro tornou-se uma grande árvore. Até que um dia o rapaz quis falar com o mestre:

- Mestre, há três anos eu pego a vaca nos braços e pulo sobre a 
árvore. $\mathrm{O}$ senhor não acha que eu já sou forte o suficiente par aprender a lutar?

- Você não precisa aprender mais nada. Seu treinamento na arte da luta já está completo. Agora você tem força suficiente para reconquistar o que deseja. Leve a vaca com você e utilize-a para cultivar a terra.

- Mas... eu não aprendi nada de arte marcial! O que devo fazer se meu irmão vier me bater?

- Não se preocupe. Se seu irmão vier lhe bater de novo, pegue a vaca no colo e corra em sua direção. Não haverá luta!

Desconfiado, o rapaz temeu estar sendo vítima de algum tipo de piada. Mesmo assim, puxou a vaca e deixou o templo Shaolin. Chegando em suas terras, começou a cultivá-las. $\mathrm{O}$ irmão mais velho, assim que soube da volta do irmão mais novo, decidiu quebrar-lhe os ossos para que nunca mais ouse voltar.

Enquanto o irmão mais novo cultivava a terra, viu seu irmão, espumando de ódio, correndo em sua direção com um imenso porrete. Imediatamente, lembrou-se do que o mestre havia dito e pegou a vaca no colo, correndo em direção ao seu irmão, que, assustando-se ao ver aquela cena inesperada e não sabendo que o irmão tivesse tanta força, amedrontado, saiu correndo e nunca mais incomodou o irmão mais novo.

Como se produz o conhecimento em tal historieta? Quais as motivações do aprendiz? O jovem está na mendicância e necessita reconquistar suas terras para sair dessa situação. Esse é seu contexto de crise. Para isso, deve aprender a enfrentar seu irmão mais forte. Nesse sentido, a busca do conhecimento não se origina de uma faculdade do saber ou da vocação para o conhecimento, e sim da necessidade de reconquistar algo. $\mathrm{O}$ que se quer reconquistar?

A ambição, expressa na voz da cunhada e realizada na atitude agressiva do irmão mais velho, é determinante para as mudanças. Criado o desamor e o ódio entre os irmãos, o contrato social é facilmente rompido. O que gera esse rompimento? Um mundo sem ordem, sem forma, sem beleza, sem sabedoria, sem harmonia, sem lei. Portanto, é contra esse mundo desordenado que o irmão mais novo lutará. Assim, o que se quer reconquistar é o equilíbrio, a beleza, o saber, a harmonia, para que possam reescrever o contrato social.

Nesse sentido, conhecer não implica sanar o mal e restabelecer o amor entre as partes. Para obter as terras de volta e sair da mendicância, é preciso que o jovem se distancie do afeto que tem ao irmão mais velho e se torne tão ou mais agressivo que ele, que se torne um estranho. Diz Foucault que "é somente nessas relações de luta e de poder - na maneira como as coisas entre si, os homens entre si se odeiam, lutam, procuram 
dominar uns aos outros, querem exercer, uns sobre os outros, relações de poder - que compreendemos em que consiste o conhecimento." (FOUCAULT, 2005, p. 23). Diante disso, pode-se dizer que conhecer implica reconhecer aquilo que nos falta e marcar uma posição estratégica para a reconquista.

O restabelecimento da ordem no mundo da historieta não se faz na luta pela força, mas no efeito de certo modo de lutar que lembra brincadeiras infantis. Se há sapiência na luta é não causar outros desequilíbrios, respeitando a vida. Nesse caso, o conhecimento técnico deve funcionar como uma estratégia, a escolha de um lugar onde se possa ver o oponente e não ser surpreendido por ele; e a ação possa funcionar como tática capaz de surpreender o outro, invertendo as relações de força e sem causar maiores desequilíbrios, para que a situação possa ser estabilizada.

Uma das características instigantes dessa luta é que seu sucesso não se origina da força do guerreiro em posição desfavorável, apesar de estar relacionada a ela; nem em algo extraordinário encontrado no mundo como um presente divino dado ao injustiçado, apesar de tal estratégia estar relacionada ao acaso do encontro com o mestre Shaolin. O jovem injustiçado não é heroificado, pois não foi transformado em uma supernatureza humana potencializada à realização do bem. O conhecimento não depende das qualidades físicas e morais do aprendiz, não é uma faculdade sua, posto que o aprendiz é apenas um homem simples, injustiçado e necessitado. Do ponto de vista do ensino do teatro, esse processo desmistifica a idéia de "dom artístico". Assim, para se fazer teatro não é preciso uma mente diferenciada, mas apenas o sentimento de necessidade e falta de.

Por outro lado, o mestre não ensina nada de extraordinário, algo que não se saiba. Tornar o jovem um sujeito fisicamente forte e presenteá-lo com uma vaca é qualificar o lavrador que ele já é. Buscar uma tática não sangrenta para alcançar o equilíbrio de uma situação também é o óbvio. Mas buscar surpreender o oponente de maneira inusitada é lição básica para quem pretende fazer arte de vanguarda e não de um guerreiro comum. O mestre busca o efeito da surpresa do mesmo modo que o artista, pois sabe que é na surpresa, no choque, no vazio provocado pela "interrupção", que a experiência da transformação pode se dar. A orientação para a "cena da vaca" é motivada a partir de uma ação educativa do tipo estratégica.

Para as finalidades educativas do zen, a historieta termina com a conquista da estabilidade, sem qualquer derramamento de sangue. Nessa 
perspectiva, o ensinamento coincide com o que se quer dominar: o equilíbrio. Ensinar não é adaptar o sujeito às condições já encontradas, mas delas se utilizar a seu favor; nem é mostrar resultados de situações passadas, já dominadas; ensinar é agir nas necessidades imediatas do aprendiz, inventando estratégias para a luta em produzir o conhecimento que lhe permitirá adquirir o que lhe falta. Por essa via de análise, pode-se dizer que aprender, longe de ser informar-se, acumular ou formar alguém, é revelar necessidades e carências já existentes.

Conforme a historieta, diante do pedido do aprendiz, o mestre procura uma maneira de fazer com que ele retome seu ofício de lavrador. Ao nos apresentar certa maneira de aproximar "salgueiro", "vaca" e "força física" de uma cena de teatro, além de mostrar o hieróglifo da identidade do aprendiz, o mestre diferencia conhecimento técnico de saber. O movimento que faz o aprendiz é sair de si para voltar a si. Dessa maneira, o mestre mostra que seu alvo, o saber, não está na luta pela conquista da terra: o aprendiz padece de sua própria identidade e isso lhe turva a consciência de si, fato que somente poderá alcançar na experiência da luta pela própria identidade, caso isso seja possível, ou pela experiência da alteridade.

Por outro lado, a luta faz surgir um espaço, inventado, para fazer acontecer a apropriação desejada. A estratégia usada deve, no entanto, provocar o efeito surpresa, que se estende até o leitor, que ri. O momento do espanto, produzido pela historieta, é semelhante a uma cena de tragédia, pois é cômico e é trágico. No vazio que os sujeitos experimentam, conscientizam-se daquilo que os aterroriza: o medo da privação de, da ausência de.

\section{A ARTE QUE É ARTE PROVOCA CRISES}

No sentido interpretado anteriormente, a experiência da educação sofrida pelo aprendiz é da ordem do sublime. Para Lyotard, o próprio da arte é provocar esse efeito do sublime, que se aproxima de uma experiência que suspende momentaneamente a ameaça das privações, suscitando um prazer que é mais que alívio. $\mathrm{O}$ autor nos apresenta uma interessante dialética do terror aproximada aos estado das privações: "privação da luz, terror das trevas; privação do outro, terror à solidão; privação da linguagem, terror do silêncio; privação dos objetos, terror do vazio; privação da vida, terror da morte" (LYOTARD, 1997, p. 104.). Tal privação é de segundo grau, querendo com isso dizer que, no acontecimento sublime, a alma é privada da ameaça de ser privada de luz, do outro, 
de linguagem e de vida, trazendo um vazio e, portanto, a experiência do êxtase.

Ao analisar-se mais de perto aquilo que Lyotard chama de "alma", percebe-se que, se ela precisa sofrer a privação da "ameaça da privação" para se libertar do terror, é porque está carnalmente ligada à ameaça da falta. Essa identificação é tal que os sujeitos não conseguem se distanciar dela, confundindo-se com ela, como se fossem constituídos da ameaça das privações, fazendo-se acreditar que poderão sucumbir sem a ameaça do medo, como se, paradoxalmente, o terror lhes protegesse. $\mathrm{O}$ mais estranho no efeito dessa privação de segundo grau é que ela não produz um sujeito renovado, um conceito novo ou um objeto precioso, ela apenas prenuncia a presença de algo que, paradoxalmente, já estava presente no acontecimento, mas que não é da ordem do visível e do comensurável.

Do ponto de vista prático, é como se os instrumentos de vigilância e outros dispositivos provassem que a natureza do homem tende para a indisciplina. Assim, todo tipo de ação antidisciplinar é julgada como vilania para que possa ser merecedora de punição. No entanto, como se viu com De Certeau, é justamente a capacidade de perceber e inventar brechas na rede de vigilância o que salva toda uma sociedade de ser sucumbida por uma ideologia.

Afinal de contas, o que é uma rede de vigilância? E como a arte pode atuar? É compactuando com aquelas "maneiras de fazer" populares observadas nas ruas, por exemplo, com a atitude do aluno que rouba o tempo da aula para desenhar em seu caderno, que se voltam os olhos do pesquisador. A arte, com sua experiência para o êxtase, o distanciamento e o sublime, não leva os indivíduos a se libertarem da ameaça da privação, mas pode fazê-los sofrer, momentaneamente, a privação desta ameaça. $\mathrm{O}$ que desencadeia, depois, é outra questão.

Aquilo a que se refere o sublime leva a pensar em eventos artísticos que possibilitem a vazão de acontecimentos que provoquem a presença do terror nos espaços da escola. Enfatiza-se a necessidade de se realizar trabalhos que tragam à tona as ameaças presentes nas relações entre os sujeitos para que possam compreender os motivos da violência consentida por eles mesmos.

É nessa direção que as formas do teatro contemporâneo provocam "interrupções" e, ao mesmo tempo, propõem a interatividade, podendo servir como aliadas poderosas para expor as contradições que geram esse estado permanente de tensão e a consciência de que os dispo- 
sitivos para a vigilância são multiplicados para a própria vigilância. Daí o receio dos educadores de trabalhar nessa perspectiva, posto haver a necessidade de se mergulhar em momentos de desconstrução para que as contradições apareçam com a força que elas possuem. Há necessidade de se estar preparado e ciente de tal travessia, pois todo desmonte de uma situação fixada faz perder os contornos de fronteiras e, com eles, vão-se as certezas. A isso se chama processo de desterritorialização, que, na lógica do vigilante disciplinador, soa como desordem. Desse modo, há que se estar preparado para enfrentar a repreensão, a represália e repressão que daí poderão surgir contra os agentes culturais. Em uma sociedade vigiada, desenvolvem-se mecanismos de silenciamento altamente sofisticados. Esse fato é inevitável, pois se trata de enfrentar processos de desmontagem de pontos fixos que a sociedade disciplinar mantém à força.

\section{REFERÊNCIAS}

ADORNO, T. Educação após Auschwitz. In: COHN, G. (Org.) Sociologia. 2 ed. São Paulo: Ática, 1994. (Grandes Cientistas Sociais).

COELHO, T. O que é ação cultural? São Paulo: Brasiliense, 2001. (Primeiros Passos).

COELHO, T. Arte pública, espaços públicos e valores urbanos. In: Guerras culturais: arte e política no novecentos tardio. São Paulo: Iluminuras, 2000.

FAVARETTO, C. F. Pós-moderno na educação? In: SERBINO, R.V.; BERNARDO, M.V.C. (Orgs.). Educação para o século XXI. São Paulo: Edunesp, 1992.

FAVARETTO, C. F. Moderno, pós-moderno, contemporâneo na educasaão e na arte. 2004 Tese (Livre-Docência), Faculdade de Educação, Universidade de São Paulo, 2004.

FAVARETTO, C. F. Unidade e multiplicidade no debate sobre o pós-moderno. In: MARTINELLI, M. L. et al. (Orgs.). O uno e o múltiplo nas relacõoes entre as áreas do saber. São Paulo: Cortez, 1995.

FOUCAULT, M. Microfísica do poder. Trad. Roberto Machado. 3 ed. Rio de Janeiro: Graal, 1982. (Biblioteca de Filosofia e História das Ciências; v. 7).

FOUCAULT, M. O que são as luzes? In: FOUCAULT, M.; DA MOTTA, M.B. (Org.). Arqueologia das ciências e bistória dos sistemas de pensamento. Rio de Janeiro: Forense Universitária, 2000. (Ditos e Escritos v.2).

FOUCAULT, M. A verdade e as formas jurídicas. Trad. Roberto C. M. Machado e Eduardo J. Morais. 3 ed. São Paulo: Nau, 2005.

GAGNEBIN, J. M. História e narração em Walter Benjamin. 2 ed. São Paulo: Perspectiva, 2004. (Estudos).

GAGNEBIN, J. M. Sete aulas sobre linguagem,memória e bistória. Rio de Janeiro: Imago, 2005. GOERGEN, P. Pós-modernidade, ética e educaşão. Campinas: Autores Associados, 2001.

KASTRUP, V. A invenção de si e do mundo. Uma introdução do tempo e do coletivo no estudo da cognição. Campinas: Papirus, 1999.

LARROSA, J. Pedagogia profana. Danças, piruetas e mascaradas. Trad. Alfredo VeigaNeto. 4 ed. Belo Horizonte: Autêntica, 2004.

LARROSA, J. Experiência e paixão. In: Linguagem e educação depois de Babel. Trad. Cyntia 
Faria. Belo Horizonte: Autêntica, 2004.

LEHMANN, H-T. Teatro pós-dramático e teatro político. Trad. Rachel Imanishi. Sala Preta 3. Revista do Departamento de Artes Cênicas da ECA-USP. São Paulo: 2003.

LYOTARD, J-F. O pós-moderno. Trad. Ricardo C. Barbosa. Rio de Janeiro: Olympio, 1986.

LYOTARD, J-F. O Inumano. Trad. Ana Cristina Seabra e Elisabete Alexandre. 2 ed. Lisboa: Estampa, 1997.

LYOTARD, J-F. O pós-moderno explicado às crianças. Correspondência 1982-1985. Trad. Tereza Coelho. 2 ed. Lisboa: Dom Quixote, 1993.

\section{NOTAS}

1 OITICICA, Hélio. Experimentar o experimental. Arte em Revista, n. 5. 1981.

2 GUÉNOUN, Denis. O teatro é necessário? São Paulo: Perspectiva, 2004. (Debates).

${ }^{3}$ A ação cultural caracteriza-se por ações cuja finalidade é aproximar o que está separado no campo da cultura.

4 O Panóptico é um modelo prisional, do século XVII, elaborado Geremy Bentham. Segundo Foucault, o panóptico despertou interesse, pelo fato de ser aplicável a muitos domínios diferentes. Não se tratava apenas de uma prisão. O panóptico, é um princípio geral de construção, um dispositivo polivalente de vigilância, uma máquina óptica universal das concentrações humanas. http://www.educ.fc.ul.pt/docentes/opombo/ $\mathrm{hfe} /$ momentos/soiedade\%20disciplinar/index.htm

${ }^{5}$ Desde 2004, sou integrante do Grupo Alerta! que executa intervenções e performances em espaços públicos. Blog: alerta_alerta@yahoogrupos.com.br

${ }^{6}$ www.barbatuques.com.br

Recebido: $21 / 01 / 2008$

Aprovado: 16/04/2008

\section{Contato:}

Rua Ilha do Piraquê, 36

Sousas - Campinas

São Paulo

Brasil

CEP 13104-110

E-mail: carminda.stenio@uol.com.br 